\title{
Key opinion leaders reach an evidence-based consensus on mouthwash use
}

On 29 October 2021, a group of key opinion leaders (KOLs) gathered on the Southbank in London with Johnson \& Johnson Ltd. for their 2021 National Advisory Panel event.

These events and the relationships with the KOLs provide insight into how Johnson \& Johnson Ltd. can best support primary care dental professionals in maintaining and improving the oral health of their patients, as well as building on the company's continuing supportive partnership.

The overarching aim of the event was to seek the KOLs' views in relation to supporting and maintaining oral health in patients between appointments, specifically looking at mechanical cleaning, any limitations, and possible adjunctive support in the form of a chemotherapeutic mouthwash.

They agreed on the following evidence-based consensus on mouthwash use:

'Healthy gums don't bleed. Effective toothbrushing and interdental cleaning is essential for keeping gums healthy. Mouthwashes containing fluoride ( $>100$ $\mathrm{ppm} \mathrm{F}$ ) that are clinically proven to reduce plaque offer additional benefit.'

Children over the age of seven and adults: 'After brushing with a fluoride toothpaste, spit don't rinse with water and if gingival bleeding is present, use a daily fluoride-containing mouthwash that is clinically proven to reduce plaque'.

The key opinion leaders taking

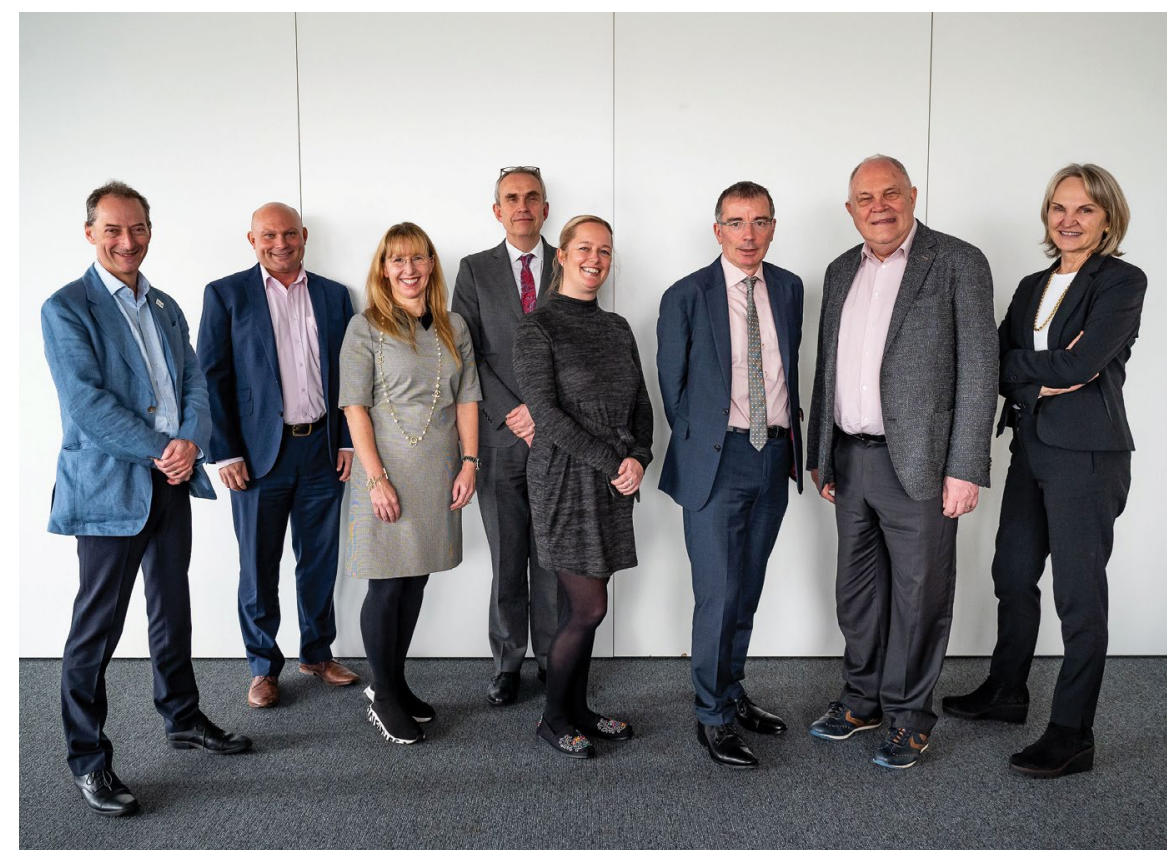

part were: Dr Nigel Carter, Oral Health Foundation; Professor Iain Chapple, University of Birmingham; Professor Chris Deery, University of Sheffield; Professor Mike Milward, University of Birmingham; Professor Anthony Roberts, Cork University Dental School and Hospital; Miranda Steeples, British Society of Dental Hygiene and Therapy; Professor Nicola West, Bristol Dental School; and Professor Helen Whelton, University College Cork.

Presentations were made by Iain Chapple, who looked at the global economic impact of periodontal disease; Anthony Roberts, who offered a fresh perspective on periodontal health and disease; and Chris Deery, who spoke on the current situation in relation to caries.

Following each presentation, there was a group discussion and a review of the evidence. Ultimately, the KOLs concluded there was a perceived need for simple recommendations to help dental professionals support their patients' plaque management efforts to best effect and therefore created the above consensus statement.

Johnson \& Johnson Ltd. looks forward to continuing to work in partnership with dental professionals following the insights gained from this National Advisory Panel.

\section{Complimentary digital excellence events}

Align Technology, Inc. has announced the third season of its Digital Excellence Series, a webinar programme that underlines the significance and relevance of digitalisation and how it can support treatment outcomes, improve collaboration with laboratories, and optimise dental practice efficiency and workflows.

The Digital Excellence Series will feature new digital opportunities and best practice examples for dental professionals who are already working with an intraoral scanner. For those dentists yet to switch from analogue to a digitised practice environment, the series will provide advice and guidance to help make this step effective.

Dentists are invited to join experienced iTero intraoral scanner clinical speakers who will draw on their practice experience and illustrate their presentations with clinical examples to help dental professionals envision their digital futures and understand the practical steps to take.

Upcoming webinars for Q1 2022 include:

- 2 March 7.30 pm: Dr Marcos White (UK) and Dr Kristina Baumgarten (DE), both general practitioners, will share guidance about how to implement a digitally optimised new patient experience and discuss the impact its made in their own dental practice.

All events are complimentary and will be conducted in English with simultaneous live translations into French, Italian, German, Spanish, Polish, Russian and Turkish.

Visit https://des.itero.com/des for full details. Registration required. 